\title{
Development of MGDA Software for Calculation of Patient Specific Mean Glandular Dose during Mammography
}

\author{
1Meherun Nahar, ${ }^{2}$ M Sazzad, ${ }^{3}$ Abdus Sattar Mollah and ${ }^{4}$ Mir Mohammad Akramuzzaman \\ ${ }^{1}$ Bangladesh Atomic Energy Regulatory Authority, Dhaka, Bangladesh \\ 2Department of Physics, Bangladesh Army University of Engineering \& Technology, Qadirabad Cantt. Natore, Bangladesh \\ 3Department of Nuclear Engineering and Technology, Military Institute of Science and Technology, Dhaka, Bangladesh \\ ${ }^{4}$ Department of Physics, Jahangirnagar University, Savar, Dhaka, Bangladesh
}

Correspondence Address: Dr. Meherun Nahar, Principal Scientific Officer, Bangladesh Atomic Energy Regulatory AuthorityE-12/A,

\section{INTRODUCTION}

Mammography procedure with $\mathrm{x}$-ray has experienced an enormous expansion during the last few decades. At present it is one of the most frequent $\mathrm{x}$-ray examinations in many countries and the main tool for early detection of breast cancer. Screening mammography is in progress in some of the countries with nation-wide screening programs. Though screening mammography has not been started yet in Bangladesh but frequency of mammography is still high and almost $100 \%$ are clinical investigations referred by physicians. Outside of risk factors for breast cancer associated with individual health, family history, life-style and environment, a risk that has become important in recent time is the dose received by the glandular tissues of the individual patient. In view of this, it is entirely appropriate to throw light on the importance of the physics of medical imaging and dosimetry. This work has been developed to establish an appropriate protocol for calculation of absorbed dose by breast during mammography.

The purpose of the calculations done in the present work is to evaluate the radiation dose for specific patients from mammography. Mean glandular dose (MGD) is the quantity used to express the absorbed dose by the breast to estimate the radiation risk during mammography $(1,2)$. It is difficult to measure this dose directly; hence is obtained adopting alternative procedures. MGD can be obtained by multiplying the in-air exposure on the entrance surface, i.e. entrance skin exposure multiplied by the absorbed dose conversion factor. A method of calculation of the absorbed dose conversion factor that is determined by $\mathrm{x}$-ray quality (tube voltage and half-value layer), compressed breast thickness, and breast composition has been developed in the present work. Necessary computer programmes have also been written. Calculation of MGD based on the breast composition is done by this software's. This paper is devoted to describe these calculation tools.

\section{MATERIALS AND METHODS}

\section{Mathematical algorithm for preparation of software}

\section{A. Normalized Glandular Dose}

Breast cancer almost always arises in glandular breast tissue. As a result, the mean radiation absorbed dose to glandular tissue is the preferred measure of the radiation risk associated with mammography. If the normalized mean glandular dose, $\mathrm{D}_{\mathrm{gN}_{\mathrm{N}}}$ (the mean glandular dose per unit entrance skin exposure) is known, the mean glandular dose, Dg can be calculated from the product of $\mathrm{D}_{\mathrm{gN}}$ and the breast entrance skin

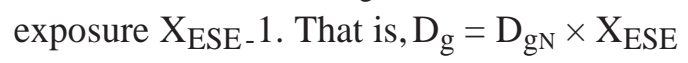

where $\mathrm{X}_{\mathrm{ESE}}$ is the entrance skin exposure (ESE) in roentgens, and $\mathrm{D}_{\mathrm{gN}}$ is normalized mean glandular dose which is the conversion factor to transfer entrance skin exposure to mean glandular dose The conversion factor $\mathrm{D}_{\mathrm{gN}}$ is determined by experimental and computer simulation methods and depends on radiation quality ( $\mathrm{kVp}, \mathrm{mAs}$ and HVL), $\mathrm{x}$-ray tube target materials, filter material, breast thickness and tissue composition. 


\section{B. Normalized Glandular Dose $\mathbf{D}_{\mathrm{gN}}$ Calculation}

The Monte Carlo procedure developed by Boone et al (3) can be used to compute the normalized glandular dose to the breast. In a Monte Carlo simulation, the average energy to the breast tissue compartment, per incident $\mathrm{x}$-ray photon was normalized by means of the energy of the incident photons (all Monte Carlo runs used monoenergetic spectra). Thus the fractional energy absorption is $\mathrm{f}(\mathrm{E})$ :

$f(E)=\frac{\text { energy absorbed per energy photon }}{\text { photon energy }}$

The value of $E$ is expressed in kilo electron volts, and the x-ray photon spectra $\Phi(E)$ is normalized to the number of photons corresponding to $1 \mathrm{R}(0.258$ $\mathrm{mC} / \mathrm{kg}$ ) (for the entire spectrum). Thus the $\mathrm{D}_{\mathrm{gN}}$ values can be expressed according to Boone et al procedure as:

$\mathbf{D}_{\mathrm{gN}}=\sum_{\mathrm{F}_{\text {min }}}^{\mathrm{E}_{\max }} \mathrm{f}(\mathrm{E}) \times \mathrm{E}\left(1.6 \mathbf{0} 2 \times 1 \mathbf{0}^{-\boldsymbol{8}}\right) \times \Phi(\mathrm{E}) \times \mathrm{G} \times \frac{\text { area }}{\text { mass }}$

Where the value of $f(E)$ is defined in Eqn. 2, the constant $\mathrm{G}$ corrects the normalized dose calculation specially to the glandular component of the breast tissue $\left(D_{g_{N}}\right)$ in heterogeneous tissue matrix and is expressed as :

$G=\frac{f_{g}\left(\frac{\mu_{e n}}{\rho}\right)_{g}}{\left[f_{g}\left(\frac{\mu_{e n}}{\rho}\right)_{g}+\left(1-f_{g}\right)\left(\frac{\mu_{e n}}{\rho}\right)_{2}\right]}$

Here the mass energy absorption coefficient $\left(\mu_{\mathrm{en}} / \rho\right)$ are specified with an 'a' subscript for adipose tissue and ' $\mathrm{g}$ ' subscript for glandular tissue.

Units for $D_{g N}$ were derived as follows: $D_{g N}$ is expressed in milliard per roentgen, $f(\mathrm{E})$ has no unit, $\mathrm{E}$ is expressed in kilo electron volts per photon, $\Phi(\mathrm{E})$ is expressed as photon per square millimeter per roentgen, $\mathrm{G}$ has no unit, area is in square millimeters and mass is in grams. The constant $1.6021 \times 10^{-8}$ was derived as follows:

$\left(1.6021 \times 10^{-8}\right) \frac{(\text { mrad g })}{\mathrm{keV}}=\left(1.6021 \times 1 \mathbf{0}^{-9}\right) \frac{\mathrm{ergs}}{\mathrm{keV}} \times \frac{1000 \mathrm{mrad}}{\mathrm{Rad}} \times \frac{\mathrm{g} \mathrm{rad}}{100 \mathrm{ergs}}$
The area in Eqn. 3 is the surface area at the top of the breast exposed to x-rays and mass is that of the purely glandular portion of the breast tissue. For a semicircular breast tissue compartment of radius $\mathrm{R}_{2}$, a breast density $\rho$, a compressed breast thickness $t$, and a skin layer thickness $t_{\text {skin }}$ the mass is given as

mass $=\mathrm{f}_{g} 1 / 2 \pi \mathrm{R}_{2}^{2}\left(\mathrm{t}-2 \mathrm{t}_{\text {skin }}\right)$ 。

\section{Calculation of Compound Density and Half Value Layer}

For a breast if it contains a weight fraction $f_{g}$ of glandular tissue and, correspondingly, a weight fraction of $\left(1-f_{g}\right)$ for adipose tissue, it can be shown that the glandular volume fraction $V_{g}$ is given by

$\mathrm{V}_{\mathrm{g}}=\left[\left\{\left(1-\mathrm{f}_{\mathrm{g}}\right) \rho_{\mathrm{g}} / \mathrm{f}_{\mathrm{g}} \rho_{\mathrm{a}}\right\}+1\right]^{-1}$

where $\rho_{\mathrm{g}}=1.04 \mathrm{gm} / \mathrm{cm} 3$ is the density of $100 \%$ glandular tissue; and $\rho_{\mathrm{a}}=0.93 \mathrm{gm} / \mathrm{cm}^{3}$ is the density of $100 \%$ adipose tissue (2). If the total volume is set to be unity $\left(1 \mathrm{~cm}^{3}\right)$, for simplicity, so that $\mathrm{V}_{\mathrm{g}}+\mathrm{V}_{\mathrm{a}}=$ $1 \mathrm{~cm}^{3}$, then the compound density can be expressed as

$\rho_{\text {compound }}=\rho_{\mathrm{g}} \mathrm{V}_{\mathrm{g}}+\rho_{\mathrm{a}} \mathrm{V}_{\mathrm{a}}$

For specific breast, $f_{g}$ represents the amount of glandular tissue. The $f_{g}$ value for individual breast was measured from studying patient image thresholding technique by using ADOBE AIR programme (4).

Calculation of HVL for different tube potentials was done through Eqn. 9 developed by Japanese researcher. For this purpose aluminum alloy sheets with $99 \%$ purity were considered. The combinations of target/filter considered were molybdenum/molybdenum (Mo/Mo), molybdenum/rhodium (Mo/Rh), and rhodium/rhodium $(\mathrm{Rh} / \mathrm{Rh})$. Tube potential was taken from the actual values considered during patient diagnostics. The relations of half value layer and tube potential are expressed by the following equations: 


$$
\begin{array}{ll}
\text { Mo/Mo } & y=0.90+0.010 x \\
\text { Mo/Rh } & y=0.253+0.0060 x \\
\text { Rh/Rh } & y=0.0740+0.0130 x \\
\text { here, } y=\text { HVL }, & x=k V
\end{array}
$$

\section{Calculation of Linear Attenuation, Mass} Attenuation and Mass Energy Absorption Coefficients Photon Fluence per Roentgen

The fraction of photons removed from a monoenergetic beam of $\mathrm{x}$-rays or gamma rays per unit thickness of material is called the linear attenuation coefficient $(\mu)$, typically expressed in units of inverse centimeters (cm-1) and related to the mass attenuation coefficient $\mu \mathrm{m}$ atomic attenuation coefficient $\mu \mathrm{a}$ and electronic attenuation coefficient $\mu$ e as follows

$\mu=\rho \mu_{m}=\frac{\rho N_{A}}{\mathrm{~A}} \mu_{\mathrm{a}}=\frac{\rho N_{\mathrm{A}} Z}{\mathrm{~A}} \mu_{\mathrm{e}}$

The linear attenuation coefficient normalized to unit density is known as mass attenuation coefficient:

Mass attcnuation coefficient, $(\mu / \rho)=\frac{\text { Linear attenuation coefficient }(u)}{\text { Density of material }(\rho)}$

Values of mass attenuation coefficient for mixture compound can be obtained according to a simple additive procedure expressed as

$(\mu / \rho)_{m i x}=\sum_{i}^{n} \mathrm{w}_{\mathrm{i}}\left(\frac{\mu}{\rho}\right)_{\mathrm{i}}$

where $\mathrm{w}_{\mathrm{i}}$ is the weight fractions for mixture compound. $\mathrm{w}_{\mathrm{i}}=1,2,3 \ldots$ are the number of components in the mixture.

The mass energy transfer coefficient, $\left(\mu_{\mathrm{tr}} / \rho\right)$ is the fraction of mass attenuation coefficient that gives rise to the initial kinetic energy of electrons in a small volume of absorber. Values of mass energy transfer coefficient for mixture compound can be obtained according to a simple additive procedure expressed as

$\frac{\mu_{e n}}{\text { Radiation }}=\sum_{\text {from an } \mathrm{x}}^{n} \mathrm{~W}_{\mathrm{i}}\left(\frac{\mu_{e n}}{\rho}\right)_{\mathrm{i}}$

Radiation from an x-ray generator or a radioactive source consists of a beam of photons, usually with a variety of energies. If we consider that the beam is monoenergetic then photon fluence, which is a measure of photon intensity per unit area per rontgen expressed as:

Photon flucnce per roentgen; $\quad \frac{\Phi}{\mathrm{X}}=\frac{0.00873 \mathrm{~J}}{\mathrm{~h} \mu\left(\mu_{\mathrm{en}} / \rho\right)_{\text {air }} \mathrm{kg} \mathrm{R}}$

\section{THE SOFTWARE}

The MGD of specific patient undergoing mammography depends on the number of parameters including normalized glandular dose $\left(\mathrm{D}_{\mathrm{gN}}\right)$, specific patient information, radiographic data, photon interaction coefficient, specific breast composition and x-ray spectrum. A software named Mean Glandular Dose Assessment (MGDA) has been developed in this work for the calculation of entrance skin exposure conversion factor/ normalized glandular dose $\left(\mathrm{D}_{\mathrm{gN}}\right)$ as well as MGD $(\mathrm{Dg})$ and other relevant parameters. The software has been developed based on, Visual Basic Language version 6.0.

In this study the specific interface was developed to calculate values of linear attenuation coefficient $(\mu)$, mass attenuation coefficient $(\mu p)$ and mass energy absorption coefficient $\frac{\mu_{\mathrm{en}}}{\rho}$ for all elements of glandular and adipose tissues for the mammographic dose calculation. Program was written using Eqns. 10, 11, and 12. Calculated weight fractions of different elements as a function of glandular weight fraction as well as compound density of study samples were taken from the work of Hammerstein et al (2). By considering specific glandular component of the study sample the linear attenuation coefficient $(\mu)$, mass attenuation coefficient $(\mu p)$ and mass energy absorption coefficient $\frac{\mu_{\mathrm{en}}}{\rho}$ for each patient were calculated.

For the calculation of $D_{g_{N}}$ in Eqn. 3 the values of $f(E)$ are the extrapolated ones taking results from the work of Boone et al. (3). Here $\mathrm{E}$ is expressed in kilo electron volts and its value was the practical ones; the $\mathrm{x}$-ray photon spectra $\Phi(E)$ are normalized to the number of photons corresponding to $1 \mathrm{R}(0.258 \mathrm{mC} / \mathrm{kg})$ (for the 
entire spectrum) as expressed as photons per square millimeter per roentgen and calculated through Eqn.13. The surface area at the top of the breast exposed to $\mathrm{x}$-rays is the measured values from patients undergoing mammography.

In Eqn. 4, the mass energy absorption coefficient $\left(\mu_{\mathrm{en}} / \rho\right)_{\mathrm{a}}$ are specified with an "a" subscript for adipose tissue and "g" for glandular tissues. $\left(\mu_{\mathrm{en}} / \rho\right)_{\mathrm{g}}$ were calculated in this work for different glandular proportion and specific energy values.

In Eqn. 6, the $f_{g}$ value for individual breast was measured from studying patient image thresholding technique by using ADOBE AIR program (4) $R_{2}$ is the semicircular breast tissue compartment radius measured during data collection, $t$ is the compressed breast thickness measured during mammography for each breast, $t_{\text {skin }}$ is the skin layer thickness considered according to literature data as $5 \mathrm{~mm}$, and $\rho$ is the breast total density addressed as compound density.

For the calculation of Mean Glandular Dose $\left(D_{g}\right)$, using Eqn. 1 the $\mathrm{X}_{\mathrm{ESE}}$ values are taken from the work of $\mathrm{Wu}$ et al (5) direct submission of these values can give the final results in the calculation using this software.

\section{Program execution}

Interface labeling for the calculation of $\mathrm{D}_{\mathrm{gN}}, \mathrm{MGD}$ and mass of glandular portion is given in Figure 1. The input values of the program calculations are shown by the blank boxes represented by 'Input', where the meaning of the terms is given. Command buttons for the program running; new calculation and shutting down of the program are all represented by $\mathrm{C}$ in the figure. Of all the three command buttons as usual the 'Result' button gives the calculated values for which the program is designed, 'New' button takes new values for further calculation of the values, and the 'End' command button finally shuts down the program after the calculation.

Table 1: Comparison of mean glandular dose (MGD) per woman, MGD per film by calculating present and other software. Data are presented as median (lower quartile and upper quartile in parentheses) and mean values (min-max)

\begin{tabular}{|c|c|c|c|c|}
\hline \multicolumn{2}{|c|}{ VGD per woman (mGy) } & \multirow[t]{2}{*}{$\begin{array}{l}\text { Conversion } \\
\text { factor used }\end{array}$} & \multicolumn{2}{|c|}{$\begin{array}{l}\text { MGD per fillu } \\
\text { (mGy) }\end{array}$} \\
\hline Median & Mcan & & Median & Mcan \\
\hline $\begin{array}{l}2.92 \quad(2.52, \\
3.46)\end{array}$ & $\begin{array}{l}3.17 \\
(1.89,696)\end{array}$ & $\begin{array}{l}\text { Calculated by } \\
\text { present software }\end{array}$ & $\begin{array}{l}1.49 \\
(1.21,1.72)\end{array}$ & $\begin{array}{l}1.61 \pm 0.6(0.84 \\
3.76)\end{array}$ \\
\hline $\begin{array}{l}2.77 \\
(2.32,3.1)\end{array}$ & $\begin{array}{l}3.06 \\
(1.73,6.67)\end{array}$ & Wu ct al (5) & $\begin{array}{l}1.42 \\
(1.07,1.65)\end{array}$ & $\begin{array}{l}1.53 \pm 0.39(0.87, \\
3.53)\end{array}$ \\
\hline
\end{tabular}

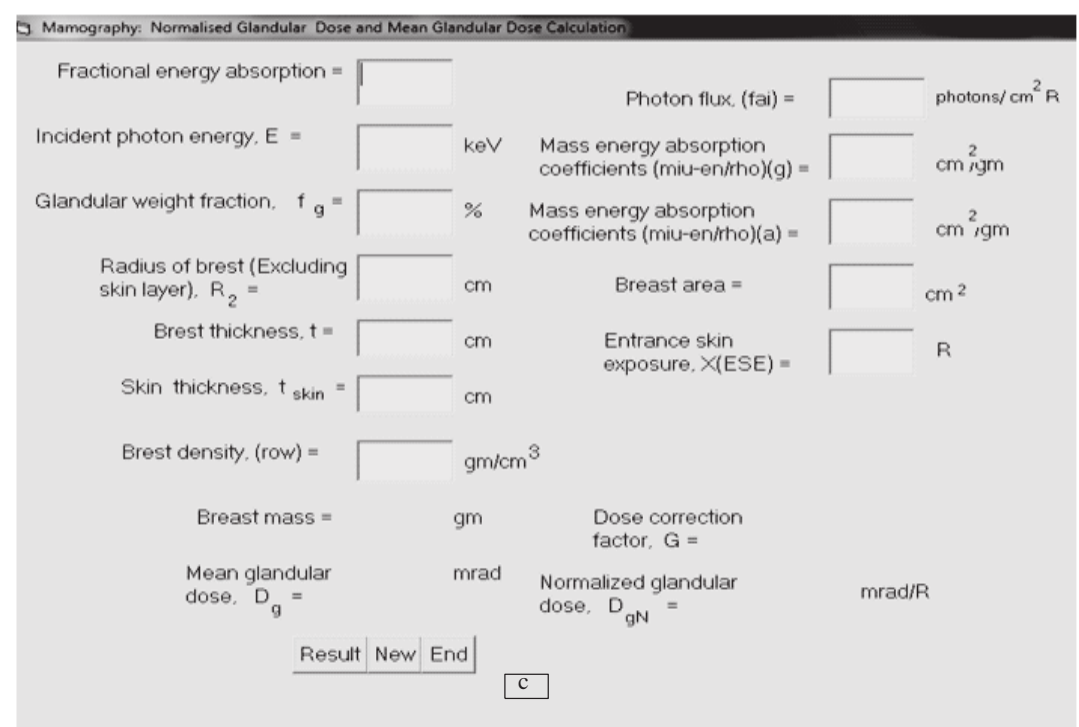

Figure1. Program labeling for the calculation of normalized glandular dose $\left(\mathrm{D}_{\mathrm{gN}}\right)$ and mean glandular dose $\left(D_{g}\right)$

\section{RESULTS AND DISCUSSION}

The software was evaluated for 40 mammograms of 20 women who underwent referral mammography in a hospital at Dhaka city from October 2010 to October 2011. MGD calculation for same woman was made by available Medical physics software developed by Sobol et al (6). Comparison result is shown in Table-1. Difference in both software calculations is within $5 \%$. The difference result in both approaches with two software can explain by the specific breast dimension for each 
patient as well as breast area and also stumbling block in attempts to calculation of mean glandular dose by interpolation of lookup values for the set of different factors. Calculation tools developed in the present work is more useful for extended estimation of MGD for specific patient with all different factors and a wide range of CBT values from $2 \mathrm{~cm}$ to $12 \mathrm{~cm}$. This software, as for the facilities to own a dosimeter, using edit command function by inputting measured HVL and the incident exposure in the air, is possible to use as the calculator.

\section{CONCLUSION}

In a facility without measurement equipment such as a dosimeter, a user can estimate the exposure dose without difficulty simply by entering the exposure conditions. Furthermore, half-value layer, and conversion factor can be calculated by using the newly developed software. This tool was extends to include normalized glandular dose, $\mathrm{D}_{\mathrm{gN}}$ values for much thicker breast (from 2-12 cm) than that of the previous work .It is possible to calculate normalized glandular dose for any breast composition within stated ranges of input parameters $(\mathrm{kVp}, \mathrm{HVL}$, breast thickness and $\mathrm{mAs})$. This technique seemed to be sufficiently useful if a user simply estimates exposure dose.

\section{REFERENCES}

1. Dance, D., Skinner, C., and Carlsson, G. Breast Dosimetry. Applied Radiation and Isotopes 1999; 50:185-203.

2. Hammerstein, G. R., Miller, D., White, D. R., Masterson, M., Woodard, H., and Laughlin, J. Absorbed Radiation Dose in Mammography. Radiology 1979; 130:485-91.

3. Boone J. Glandular Breast Dose For Monoenergetic and High-Energy X-ray Beams, Monte Carlo Assessment. Radiology 1999;213:23-3.

4. Nahar, M., Mollah, A. S., Akaramuzzaman., M. M. Development of a Quantitative Estimation of Mammographically Breast Density, Bangladesh J. Nucl. Med. 2015;18:16-20.

5. Wu X., Barnes G. T., Tucker, and D. M., Spectral Dependence of Glandular Tissue Dose in Screen-Film Mammography, Radiology, 1991;179:143-48.

6. Sobol W. T., and Wu X., Parametrization of Mammography Normalized Average Glandular Dose Tables, Med. Phys., 1997;24:547-54. 